\title{
Corrigendum: Beneficial Effects and Toxicity Studies of Xian-ling-gu-bao on Bone Metabolism in Ovariectomized Rats
}

\section{OPEN ACCESS}

Edited and reviewed by: Lyndy Joy McGaw, University of Pretoria, South Africa

*Correspondence: Jie Song momo198420@hotmail.com Xiaobin Jia

Jiaxiaobin2015@163.com

Specialty section: This article was submitted to Ethnopharmacology, a section of the journal

Frontiers in Pharmacology

Received: 09 June 2020 Accepted: 20 August 2020 Published: 09 November 2020

Citation: Wu H, Zhong Q, Wang J, Wang M, Fang F, Xia Z, Zhong $R$, Huang $H$, Ke Z, Wei Y, Feng L, Shi Z, Sun E, Song J and Jia $X$ (2020) Corrigendum: Beneficial Effects and Toxicity Studies of Xian-ling-gu-bao on Bone Metabolism in Ovariectomized Rats.

Front. Pharmacol. 11:570876. doi: 10.3389/fphar.2020.570876

\begin{abstract}
Hao Wu ${ }^{1,2,3}$, Qingxiang Zhong ${ }^{1,2}$, Jing Wang ${ }^{1,2}$, Man Wang ${ }^{1,3}$, Fang Fang ${ }^{4}$, Zhi Xia ${ }^{5}$, Rongling Zhong ${ }^{5}$, Houcai Huang ${ }^{5}$, Zhongcheng $\mathrm{Ke}^{1,2}$, Yingjie Wei ${ }^{1,2}$, Liang Feng ${ }^{1,2}$, Ziqi Shi ${ }^{1,2}$, E. Sun ${ }^{1,2}$, Jie Song ${ }^{1,2^{*}}$ and Xiaobin Jia ${ }^{1,2,3^{*}}$

${ }^{1}$ Affiliated Hospital of Integrated Traditional Chinese and Western Medicine, Nanjing University of Chinese Medicine, Nanjing, China, ${ }^{2}$ Key Laboratory of New Drug Delivery System of Chinese Materia Medica, Jiangsu Province Academy of Chinese Medicine, Nanjing, China, ${ }^{3}$ College of Pharmacy, Anhui University of Chinese Medicine, Hefei, China, ${ }^{4}$ College of Nursing, Huanghai University, Qingdao, China, ${ }^{5}$ Laboratory Animal Center, Jiangsu Province Academy of Chinese Medicine, Nanjing, China
\end{abstract}

Keywords: XLBG, ovariectomized rats, osteoporosis, toxicity test, OPG/RANKL

\section{A Corrigendum on}

Beneficial Effects and Toxicity Studies of Xian-ling-gu-bao on Bone Metabolism in Ovariectomized Rats

by Wu H, Zhong Q, Wang J, Wang M, Fang F, Xia Z, Zhong R, Huang H, Ke Z, Wei Y, Feng L, Shi Z, Sun E, Song J and Jia X (2017) Front. Pharmacol. 8:273. doi: 10.3389/fphar.2017.00273

In the original article, there was an error in Figure 9. An image of the high-dose group was inserted into the middle-dose group in the stomach row. The correct Figure 9 appears below.

The authors apologize for this error and state that this does not change the scientific conclusions of the article in any way. The original article has been updated.

Copyright $\odot 2020$ Wu, Zhong, Wang, Wang, Fang, Xia, Zhong, Huang, Ke, Wei, Feng, Shi, Sun, Song and Jia. This is an openaccess article distributed under the terms of the Creative Commons Attribution License (CC BY). The use, distribution or reproduction in other forums is permitted, provided the original author(s) and the copyright owner(s) are credited and that the original publication in this journal is cited, in accordance with accepted academic practice. No use, distribution or reproduction is permitted which does not comply with these terms. 


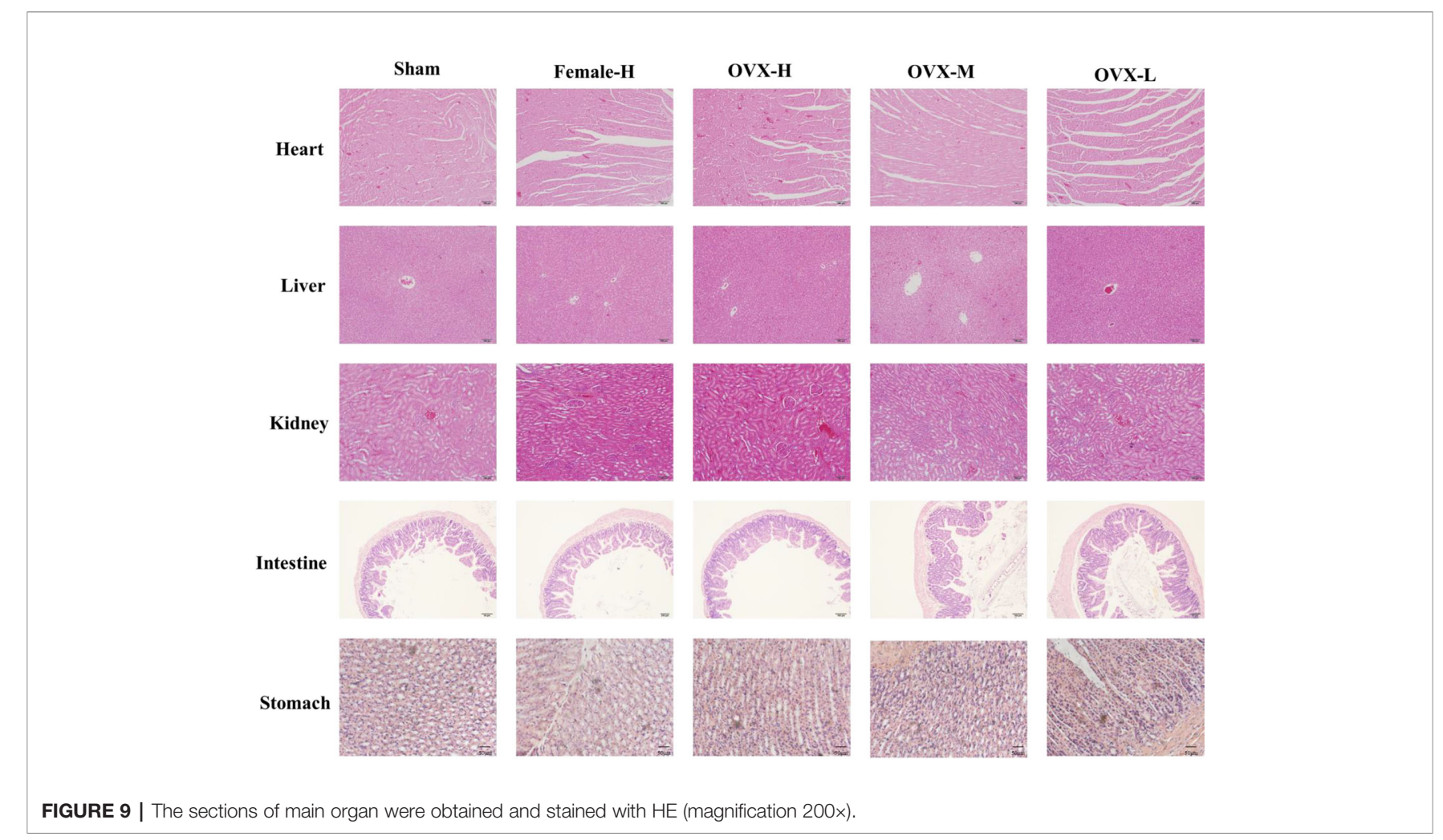

